\title{
Genome-wide identification of poplar malectin/malectin-like domain-containing proteins and in-silico expression analyses find novel candidates for signaling and regulation of wood development
}

\author{
Vikash Kumar \\ Sveriges Lantbruksuniversitet Fakulteten for Skogsvetenskap \\ Félix Barbut \\ Sveriges Lantbruksuniversitet Fakulteten for Skogsvetenskap \\ Sunita Kushwah \\ Sveriges Lantbruksuniversitet Fakulteten for Skogsvetenskap \\ Evgeniy N. Donev \\ Sveriges Lantbruksuniversitet Fakulteten for Skogsvetenskap \\ János Urbancsok \\ Sveriges Lantbruksuniversitet Fakulteten for Skogsvetenskap \\ Ewa J. Mellerowicz ( $\square$ ewa.mellerowicz@slu.se) \\ Sveriges lantbruksuniversitet https://orcid.org/0000-0001-6817-1031
}

Research article

Keywords: Populus, cell wall integrity, malectin domain, malectin-like domain, CBM57, receptor-like protein kinases, CrRLK1L

Posted Date: May 26th, 2020

DOI: https://doi.org/10.21203/rs.3.rs-28356/v1

License: (1) (i) This work is licensed under a Creative Commons Attribution 4.0 International License. Read Full License 


\section{Abstract}

Background: Malectin domain (MD) is a ligand-binding protein motif of pro- and eukaryotes. It is particularly abundant in Viridiplantae, where it occurs as either a single (MD, PF1721) or tandemly duplicated domain (PF12819) called malectin-like domain (MLD). In herbaceous plants, MD- or MLD-containing proteins (MD proteins) are known to regulate development, reproduction, and resistance to various stresses. However, their functions in woody plants have not yet been studied. To unravel their potential role in wood development, we carried out genome-wide identification of MD proteins in the model tree species black cottonwood (Populus trichocarpa), and analyzed their in-silico expression and co-expression networks.

Results: P. trichocarpa had 146 MD genes assigned to 14 different clades, two of which were specific to the genus Populus. $87 \%$ of these genes were located on chromosomes, the rest being associated with scaffolds. Based on their protein domain organization, and in agreement with the exon-intron structures, the MD genes identified could be classified into five superclades having the following domains: leucine-rich repeat (LRR)-MD-protein kinase (PK), MLD-LRR-PK, MLD-PK (CrRLK1L), MLD-LRR, and MD-Kinesin. Whereas the majority of MD genes were highly expressed in leaves, particularly under stress conditions, eighteen showed a peak of expression during secondary wall formation and their co-expression networks suggested signaling functions in cell wall integrity, pathogen-associated molecular patterns, calcium, ROS, and hormone pathways.

Conclusion: P. trichocarpa MD genes exhibit a variety of domain organizations, and include genes apparently specific to Populus, as well as genes with potential involvement in signaling pathways regulating secondary wall formation.

\section{Background}

Plant cells are surrounded by cell walls made of cellulose, hemicelluloses, pectins and structural proteins, with lignin being present in cell types specialized for mechanical support (sclerenchyma) and water transport (xylem). Cell wall biosynthesis needs to be regulated so that its mechanical properties can be adapted to different circumstances according to the signals perceived. It is becoming generally accepted that there is constant feedback from the wall to the protoplast, mediated by different molecular pathways commonly termed cell wall integrity (CWI) signaling (Hématy et al., 2007; reviewed by Wolf and Höfte, 2014; Hamann, 2015; Voxeur and Höfte, 2016; Wolf, 2017; Rui and Dinneny, 2020). Perception of signals external to the protoplast is usually mediated by plasmalemma-localized proteins with various ectodomains. One large group of ectodomain-containing proteins is the receptor-like kinases (RLKs) that allow the plant cells to perceive external cues and transduce them, using a phosphorylation relay, into signals to initiate cellular responses (Gish and Clark, 2011; Engelsdorf and Hamann, 2014). Plant RLKs belong to the RLK/Pelle kinase family, one of the largest gene families in plants with more than 600 members in Arabidopsis (Shiu and Bleecker, 2001; 2003). It comprises both RLKs and receptor-like cytoplasmic kinases (RLCKs), and has been divided into 45 subfamilies, including wall-associated kinases, extensin-like RLKs, lectin RLKs, and leucine-rich repeat RLKs. RLCKs are cytoplasmic kinases without a transmembrane domain (TMD) and they recognize signaling molecules intracellularly. The RLKs usually function as heterodimers: one subunit with a large extracellular domain interacts with a ligand, and the other, which has a smaller extracellular domain, stabilizes this interaction and enhances signal transduction (Xi et al., 2019).

Among the different clades of plant RLKs, the Catharanthus roseus receptor-like kinase 1-like proteins (CrRLK1Ls) have received significant attention as mediators of CWI (reviewed by Wolf and Höfte, 2014; Li et al., 2016; Franck et al., 2018). The family is conserved in all Streptophytes analyzed so far, including moss and liverwort, indicating its ancient origin (Galindo-Trigo et al., 2016). CrRLK1 Ls are characterized by two malectin ectodomains (MDs) forming a malectin-like domain (MLD), a transmembrane helix and a C-terminal intracellular Ser and Thr kinase domain. The Arabidopsis genome contains 17 CrRLK1L genes and the majority of them have been functionally analyzed. THESEUS1 (THE1) was the first member to be identified as a mediator of dwarfism and ectopic lignification induced by defects in cellulose biosynthesis (Hématy et al., 2007; Merz et al., 2017). Other members of CrRLK1L family including CURVY1 (CVY1), FERONIA (FER) and ANXUR1 (ANX1) are required for polar cell growth in different cell types. FER, ANX1/2 and BUDDHA'S PAPER SEAL1 and 2 (BUPS1 and 2) participate in sexual reproduction. FER mediates signaling by reactive oxygen species (ROS) and $\mathrm{Ca}^{2+}$ during pollen tube reception at the filiform apparatus (Escobar-Restrepo et al., 2007), whereas ANX1/2 together with BUPS1/2 form a receptor complex for RAPID ALKALINIZATION FACTOR (RALF) 4 or 19 in the growing tip of pollen tube and regulate ROS and $\mathrm{Ca}^{+2}$ gradients essential for its growth and CWI (Ge et al., 2017). In addition, CrRLK1L proteins are involved in immune responses. FER positively regulates pathogen-associated molecular pattern (PAMP) - triggered immunity (PTI) by facilitating the formation of a receptor complex composed of BAK1-FLS2-FER or BAK1-EFR-FER (Stegmann et al., 2017), whereas ANX1 functions antagonistically in PTI and inhibits effector-triggered immunity (ETI) (Mang et al., 2017). The downstream responses of CrRLK1Ls are

Page $2 / 22$ 
diverse and include Rho-GTPases activating NADPH oxidases involved in the production of apoplastic ROS (Foreman et al., 2003; Duan et al., 2010; Denness et al., 2011; Boisson-Dernier et al., 2013), RLCKs (Boisson-Dernier et al., 2015; Du et al., 2016), inhibition of the proton pump AHA1 (Haruta et al., 2014), $\mathrm{Ca}^{+2}$ signaling mediated by MLO proteins (Kessler et al., 2010; Meng et al., 2020), as yet unknown $\mathrm{Ca}^{+2}$ channels and a signaling cascade via intracellular kinases that eventually activate or repress gene transcription (Franck et al,. 2018).

The MLD, which is characteristic of CrRLK1L proteins, and the MD, are also found in other types of plant RLKs (Zhang et al., 2016; Bellande et al., 2017). The MD was first identified in the protein called malectin residing in the endoplasmic reticulum of Xenopus laevis and other animals, where it monitors protein glycosylation by binding di-glucose motifs with a 1,4-, a 1,3-, and a 1,2-linkage in glycosylated proteins (Schallus et al., 2008; 2010). However, the crystal structure of MLD in ANX1, ANX2, and FER indicated an absence of the aromatic residues that interact with di-glucosides in animal MDs, and suggested different ligand specificities and/or functions of the MLDs in these proteins (Du et al., 2018; Moussu et al., 2018; Xiao et al., 2019). Several peptides from the RALF family have been demonstrated to bind to ectodomains of CrRLK1L proteins in Arabidopsis: RALF34 to THE1 (Gonneau et al., 2018), RALF1, -17, -23, -32 and -33 to FER (Haruta et al., 2014; Stegmann et al., 2017), and RALF4 and -19 to the ANX1/2-BUPS1/2 receptor complex (Ge et al., 2017). Recently it has been shown that the binding of RALF23 to FER is stabilized by interaction with LORELEI-like GPI-ANCHORED PROTEINS (LLGs) and the formation of such a heterocomplex is required for PTI signaling (Xiao et al., 2019). Moreover, the ectodomain of FER has been shown to bind to the leucine-rich repeat (LRR) domain of LRR-extensin 1 (LRX1) (Dünser et al., 2019) and to pectin (Feng et al., 2018).

MD is classified as CBM57 in the CAZy database (http://cazy.org). Interestingly, the CBM57 family is greatly expanded in the model tree species Populus trichocarpa compared to the herbaceous model plant Arabidopsis thaliana (Kumar et al., 2019). Moreover, transcript of the CBM57 family members are highly upregulated in developing wood tissues of Populus tremula (Kumar et al., 2019) and Eucalyptus grandis (Pinard et al., 2015). These data suggest that MD/MLD-containing proteins (subsequently called MD proteins) have important functions in trees. We hypothesize that MD proteins are involved in the regulation of cell wall formation during secondary growth via pathways analogous to those reported for primary growth (Wolf and Höfte, 2014; Hamann, 2015; Li et al., 2016; Wolf, 2017), and that they participate in signaling cascades related to stress responses and developmental processes in trees. To find candidates for receptors active during secondary growth, we first carried out genome-wide identification of $P$. trichocarpa genes with predicted MD and MLD. Second, we used expression datasets from different organs (Sundell et al., 2015, Immanen et al., 2016) and high-resolution expression data for wood developmental zones in P. tremula (Sundell et al., 2017) to identify those MD proteins that are expressed during wood biosynthesis, and to classify them according to expression at specific stages of xylogenesis. Finally, we identified co-expression networks for the MD proteins expressed during secondary wall deposition, which include their putative interactors. Our analyses provide a framework within which to identify CWI monitoring, stress-response, and other signaling pathways operating during wood development.

\section{Results And Discussion}

\section{Identification of MD proteins in P. trichocarpa and their classification}

Searches of the $P$. trichocarpa and $A$. thaliana genomes for MD proteins resulted in the identification of 146 and 87 gene models respectively (Table S1 and S2). Previous analyses identified 62 MD genes in strawberry (Zhang et al., 2016), 74 in A. thaliana (Bellande et al., 2017; Sultana et al., 2019), and 84 in rice (Jing et al., 2020).

The $P$. trichocarpa proteins identified were analyzed for sequence similarity using protein sequence alignment and phylogenetic analysis, revealing the presence of 12 clades supported by at least $87 \%$ of bootstrap replicates, and three ungrouped sequences, two of which had orthologous sequences in A. thaliana, and were therefore considered to be two single member clades III and XI (Fig. 1 and 2). The sequences were numbered PtMD1 to PtMD146 according to their sequential appearance in the intraspecific phylogenetic tree (Fig. 1). The predicted protein properties and probable subcellular localizations of PtMD proteins are listed in Table S1. The deduced sequence lengths ranged from 274 to 1192 amino acids, and isoelectric points (pls) ranged from 4.55 to 9.49. Seventy-six out of the 146 PtMD proteins had a signal peptide (SP) cleavage site. The SP was not found in any members of clades I and XIV. Thirteen of the PtMDs were predicted to be soluble proteins, with the predicted localization of six of them being extracellular, six - including all members of clade XIV - being cytoplasmic and one being peroxisomal. Out of 133 membrane proteins, one was predicted to localize in the endoplasmic reticulum. 
127 out of the 146 poplar MD gene models were mapped to chromosomes, while 19 gene models were located on five different scaffolds (Fig. 4). The majority of chromosomal genes (79) were present in clusters comprising between two and eleven genes (Fig. 4; Table S3). Clusters were also present on the scaffolds. The clusters consisted of tandem repeats having the same or reverse orientations. This large number of tandem duplications strongly suggests that the main mechanism of MD family expansion in $P$. trichocarpa is via local gene duplication, rather than whole genome duplications. Gene multiplication at a given locus could occur via an unequal crossing over mechanism, which after multiple rounds would result in large numbers of tandemly repeated sequences. Such a mechanism was proposed as featuring particularly prominently in various $L R R$ gene families (Schaper and Anisimova, 2015) including LRR-RLK (Shiu and Bleeker 2001; Zan et al., 2013; Zulawski et al., 2014; Zhang et al., 2016, Wang et al., 2019a) and $R$ genes (Choi et al., 2016). Indeed, 11 out of our 16 clusters of PtMD genes had members with LRR domain(s) (Table S3).

Tandem duplications allow rapid gene family expansion and the creation of novel alleles and are thought to be particularly important for the co-evolution of $R$ and Avr genes in hosts and their parasites (Holub 2001; Choi et al., 2016). Partial duplications with omission of some domains form a key mechanism for neofunctionalization. Such a process apparently characterized the poplar MD family, since there were seven out of 16 clusters that included genes with LRR and kinase domains along with closely related members without LRR domains (Fig. 4; Table S3).

\section{Analysis of exon-intron structures of PAMD genes}

Exon-intron structure reflects the evolutionary history of genes; hence we analyzed the exon-intron organization of PtMDs. Although the majority of clades displayed very diverse numbers of introns (Table S4; Fig. 1), the maximum number of introns for clades within a superclade was similar. The superclade LRR-MD-PK, comprising clades I-VIII, had genes with very large numbers of introns (maximum between 23 and 26); superclade MLD-LRR-PK (clades IX-XI) had at most 15 introns; superclade MLD-PK (clade XII or the CrRLK1L group) contained genes with up to two, but typically without any, introns; and superclades MLD-LRR (clade XII) and MD-Kin (clade XIV) had at most 10 and 17 introns respectively (Table S4; Fig. 1). Lack, or low frequency, of introns in CrRLK1L genes has also been observed in other species including strawberry, Arabidopsis and rice (Zhang et al., 2016; Bellande et al., 2017; Jing et al., 2020). Thus the exon-intron organization of poplar MD genes supported their grouping into superclades, which represent ancestral diversification of plant MD genes.

The phylogenetic tree of MD proteins was generally consistent between $P$. trichocarpa and $A$. thaliana with bootstrap values of greater than $76 \%$ for the main clades (Fig. 2). Three exceptions were noted, however: one orphan protein PtMD89, clade VI that included PtMD41-PtMD56, and clade VIII with PtMD62-PtMD71. These poplar genes apparently did not have orthologs in A. thaliana. Close homologs to PtMD89 were found primarily among other trees, such as several Populus and Prunus species, Quercus suber, and Juglans regia, suggesting that PtMD89 may have a specialized function in trees. Clade VI included clusters of tandemly duplicated genes located on chromosome 19 (Fig. 4; Table S3). BLAST searches using the PLAZA database (https://bioinformatics.psb.ugent.be/plaza/) revealed the presence of similarly replicated genes in some other species, such as Hevea brasiliensis, Manihot esculenta, Ricinus communis and Prunus persica, but not in Arabidopsis. Clade VIII is specific to some Rosids, where its genes are also tandemly and block duplicated. The largest representation of this clade outside poplar is found in Hevea brasiliensis and Citrus clementina, but there are no representative genes in Arabidopsis or other Brassicaceae. Taking into consideration the conclusion that the genes of clade VI and VIII had apparently undergone tandem duplication events in the $P$. trichocarpa lineage after its separation from that of $A$. thaliana, it is possible that they represent specialized genes, such as $\mathrm{R}$ genes important for immunity, that co-evolved with poplar symbionts and/or pathogens (Holub, 2001).

Besides identifying clades not represented in Arabidopsis, we found that the relative clade sizes (number of genes per clade relative to genome size) show some differences between the two species (Fig. 2). Clade IX was expanded in A. thaliana, whereas clade I was expanded in P. trichocarpa $\left(\mathrm{c}^{2}\right.$ test at $\left.\mathrm{P} \leq 0.05\right)$.

\section{Expression of PTMDs in different organs of Populus}

RNA sequencing datasets available for aspen species were analyzed to reveal differential expression of PtMD genes among different organs and tissues. Out of the 146 genes, 145 were expressed at least in one of the organs and tissues tested, and the variancestabilized transformation (VST) of expression values are shown in Table S5. Interestingly, the majority of PtMD genes (101) showed maximum expression in leaves. Moreover, many of them showed the highest expression in leaves exposed to abiotic/biotic stress, such as beetle (32), drought (8) or mechanical damage (11). Nine PtMD genes were most highly expressed in roots exposed to drought. Genes with maximal expression values detected in stressed organs were distributed among clades I, II, IV, V, VI, VII, VIII, X, XII, and XIII (Fig. 2), suggesting stress-response functions for these clades. Interestingly, no gene that was maximally expressed in stressed organs was 
found in clades III, IX, XI or XIV, suggesting their involvement in other types of signaling. Several PtMD genes were most highly expressed in the vegetative growing organs: young roots (11) or leaves (4) (Fig. 5; Table S5: "root-control" and "expanding leaves", respectively). Eight genes, all from clades XII and XIII, were most highly expressed in female flowers at various developmental stages, and four in mature seeds. The genes highly expressed in expanding female flower buds or in mature seeds were in many cases also highly expressed in developing secondary tissues, vascular cambium or developing secondary xylem and phloem (Fig. 5 and Table S5).

\section{PtMDs involved in wood biosynthesis}

To investigate the expression of PtMDs during different stages of wood biosynthesis, we used the AspWood database (http://aspwood.popgenie.org/aspwood-v 3.0/), which provides data on high-spatial-resolution transcript abundance in developing secondary xylem and phloem tissues of aspen (Sundell et al., 2017). Only 89 PtMDs (61\%) were found to be expressed in developing secondary vascular tissues (Table S6), with the majority exhibiting distinct patterns of expression, clustering in ten expression groups (Table S6; Fig. 6). This clustering indicates that certain sets of PtMDs have specific functions at certain stages of secondary vascular development. Some of the PtMD genes expressed in secondary vascular tissue also exhibited high expression under diverse stress conditions in leaves or roots (Table S6, Fig 2).

The largest group of PtMD genes (50) that were expressed in secondary vascular tissue showed a peak of expression in the phloem (Table S6; Fig. 4). These genes were mostly from superclades LRR-MD-PK, MLD-PK (CrRLK1L), and MLD-LRR-PK. Cambium and radial expansion zones were the zones characterized by the greatest variety of PtMD transcripts including members of superclades MD-Kin, LRR-MD-PK, MLD-LRR, and MLD-PK (CrRLK1L). In contrast, PtMD genes having a peak of expression at the transition between primary and secondary wall deposition were mostly from the MLD-PK (CrRLK1L) group. Intriguingly, the genes with maximum expression during secondary wall deposition were expressed at relatively low levels and many of them belonged to clade I of PtMDs, which lacks LRR. PtMD genes with the highest expression in the maturation zone were mostly from clades V and XII.

\section{Networks of xylogenesis-related PtMD genes}

To find putative partners involved in signaling pathways together with the xylogenesis-related PtMD genes, we analyzed co-expression networks of PtMD genes identified as being expressed during xylogenesis. Ten PtMD genes having a peak of expression in the cambiumradial expansion zone and primary to secondary transition zone (CA-RE/PW-SW), and eight genes from clusters PW-SW/Secondary Wall and Secondary Wall (Fig. 6, Table S6), representing, respectively, the early and main stages of secondary wall deposition were used as baits for network analyses.

The baits for the CA-RE/PW-SW zones formed five separate networks (Fig. 7A; Table S7), the largest being that of PtMD126- one of the two poplar orthologs of AtFER. It included several candidates for functioning in signaling by phosphate relay and ROS, and for regulation of cell wall development. Apoplastic ROS in wood forming tissues could have a double role, in signaling and in regulation of lignin polymerization. Thus the PtMD126 network included a homolog of PBS1-LIKE 19 (AtPBL19), encoding a RLCK of subfamily VII-4, which signals a response to chitin perceived by CHITIN ELICITOR RECEPTOR KINASE 1 (AtCERK1) through a phosphate relay (Bi et al., 2018), and ROS production (Rao et al., 2018). Homologs of AtTGA1 and AtTGA7, which encode basic leucine zipper transcription factors involved in oxidative-stress mediated responses to biotrophic and necrotrophic pathogens (reviewed by Gatz, 2013), were, respectively, positively and negatively correlated with PtMD126 (Fig. 7A; Table 1). The oxidation state of AtTGA1 is regulated by a glutaredoxin, AtROXY19 (Li et al., 2019), the homolog of which has been found to respond to altered secondary wall xylan in aspen (Ratke et al., 2018), suggesting that the PtMD126 network might include candidates for sensing secondary wall integrity. AtTGA1 interacts with the BLADE-ON-PETIOLE 1 and 2 (AtBOP1/2) transcription factors (Wang et al., 2019b), which are known to regulate xylem fiber differentiation (Liebsch et al., 2014). Moreover, the network includes a homolog of the BEL 1-LIKE HOMEODOMAIN 8 (AtBL H8) transcription factor, which controls expression of BOP1 (Khan et al., 2015) (Fig. 7A; Table 1). The network also includes a homolog of the gene encoding GROWTH-REGULATING FACTOR9 (AtGRF9), a 14-3-3 protein that regulates developmental programs and stress signaling by binding phosphoproteins and regulating their activities (Mayfield et al., 2007; Liu et al., 2014; Omidbakhshfard et al., 2018). The presence of a homolog of IMPORTIN $b-4$ (AtIMB4), which is required to transport GRF-INTERACTING FACTOR 1 (AtGIF1) to the nucleus (Liu et al., 2019) (Fig. 7A; Table 1) further supports the involvement of GRF/ 14-3-3 genes in the PtMD126 network.

A separate large network was formed by neighbors of PtMD98 - one of the two poplar orthologs of AtTHE1 (Fig. 7A; Table 1; Table S7). This network comprised genes related to hormonal signaling by IAA and GA, and to the regulation of xylogenesis. One example is a homolog of AtLAX3, which encodes an auxin influx carrier (Swarup et al., 2008). Another is a homolog of AtAGC1-12, encoding a kinase phosphorylating the auxin efflux carrier AtPIN1 (Haga et al., 2018). We have also identified a homolog of AtGASA4 involved in GA 
responses and redox regulation (Rubinovich and Weiss, 2010). It is noteworthy that GA responses and GASA genes were also found to be upregulated in response to a secondary wall xylan defect in aspen (Ratke et al., 2018). Moreover, the co-expression network included an LRR-RLK homologous to AtPXY-CORRELATED 1 (AtPXC1), which is required for secondary wall deposition (Wang et al., 2013).

The network of PtMD94 - the clade XII member related to AtHERK1 and AtCVY1 - included a homolog of AtRALFL31 (Fig. 7A; Table 1; Table S7). RALF genes encode hormone peptides that signal developmental processes and stress responses by interacting with CrRLK1Ls. AtRALFL31 belongs to subfamily IIIA which includes as yet uncharacterized members, but both AtRALFL31 and Potri.017G059500 have the conserved YISY motif essential for interaction with AtFER (Campbell and Turner, 2017). Thus, Potri.017G059500 could potentially encode a peptide hormone recognized by PtMD94. The PtMD94 network also included other candidates for signaling. For example, there was a homolog of PLANT U-BOX 13 (AtPUB13), which encodes an E3 ligase involved in signal-activated ubiquitination and subsequent degradation of different receptors including ABA INSENSITIVE 1 (AtABI1) (Kong et al., 2015), BRASSINOSTEROID INSENSITIVE 1 (AtBRI1) (Zhou et al., 2018), LYSM-CONTAINING RECEPTOR-LIKE KINASE 5 (AtLYK5) (Liao et al., 2017), and FLAGELLIN-SENSITIVE 2 (AtFLS2) (Liu et al., 2012; Antignani et al., 2015). The ubiquitination of flg22-bound AtFLS2 by AtPUB13 depends on its interactor protein RAB GTPASE HOMOLOG A 4B (AtRABA4B) (Antignani et al., 2015). Interestingly, a homolog to another PtMD94 network member encodes ROOT HAIR DEFECTIVE 4 (AtRHD4) which mediates polar localization of AtRABA4B (Thole et al., 2008). Consequently, it seems likely that these PtMD94 network members are indeed functionally linked within the same network.

Two other PtMD genes expressed during early secondary wall biosynthesis, PtMD88 and PtMD145, formed small networks, which included important regulatory genes in xylem cell differentiation (Fig. 7A; Table 1; Table S7). One of them was the homolog of the master spatial regulator of vascular differentiation, PHLOEM INTERCALATED WITH XYLEM (AtPXY), encoding an LRR-RLK which signals tracheid fate upon binding the small CLE peptide AtTDIF (Fisher and Turner, 2007). The other was a homolog of VASCULAR-RELATED RECEPTOR-LIKE KINASE 1 (AtVRLK1) (Huang et al., 2018) which is probably responsible for the switch between xylem cell expansion and secondary wall deposition.

The late secondary wall-expressed baits formed five networks (Fig. 7B; Table 1; Table S8). The largest of these was associated with two PtMD genes, PtMD129, a clade XII member related to AtANX1 and AtANX2, and PtMD137, which encodes an LRR-RLK, from clade XIII. Orthologs of key signaling-related genes were included within this network. One of them was CALCIUM PERMEABLE STRESS-GATED CATION CHANNEL 1 (AtCSC1). Stretch-activated $\mathrm{Ca}^{2+}$ channels have been predicted to be important players in CWI (Engelsdorf and Hamann, 2014). AtCSC1 belongs to a newly characterized family of stretch-activated $\mathrm{Ca}^{2+}$ channels conserved in eukaryotes (Hou et al., 2014; Liu et al., 2018). In addition, we found Potri.015G108700/AT5G61820, encoding an uncharacterized NOD19-like protein, which has been implicated in responses to cold stress downstream of mechanosensitive $\mathrm{Ca}^{2+}$ channels (Mori et al., 2018). The aspen homolog of AtCSC 1 is thus a promising candidate for a secondary wall damage sensor. Another important signaling-related homolog is TAPETUM DETERMINANT 1 (AtTPD1), which encodes a small peptide hormone that is recognized by an RLK complex consisting of AtEMS1 and AtSERK1/2 to activate transcription factors of the BES1 family (Chen et al., 2019). Moreover, a homolog of Arabidopsis ROP (RHO OF PLANTS) GUANINE NUCLEOTIDE EXCHANGE FACTOR 7(AtROPGEF7) was among the hits for PtMD137. AtROPGEF7 interacts with the kinase domain of AtFER, mediating downstream NADPH oxidase-dependent ROS signaling which is needed for polarized cell growth (Duan et al., 2010). Finally, we identified a homolog of Arabidopsis GT-2 Like (AtGT2L), which encodes a Ca ${ }^{2+}$-dependent calmodulin (CaM)-binding trihelix transcription factor involved in plant abiotic stress signaling (Xi et al. 2012). In addition to signaling-related genes, the PtMD129-PtMD137 network included some key cell fate regulator proteins (Fig. 7B; Table 1; Table S8). One of these was the homolog of WIP DOMAIN PROTEIN 5 (AtWIP5), which encodes a zinc-finger protein involved in root patterning downstream of auxin (Crawford et al., 2015) and ROS signaling (Miao et al., 2004). Another was a homolog of Arabidopsis SQUINT (AtSQM), which encodes a cyclophilin 40-like protein that promotes the accumulation of miRNAs miR156 and miR172, targeting master regulatory genes in organ development (Smith et al. 2009; Prunet et al., 2015). The network also included orthologs of two genes encoding master transcriptional regulators, AtMYB46 and AtMYB83, which activate the secondary wall program (Zhong and Ye, 2012). Both these genes showed positive correlation with PtMD129. In contrast, orthologs of three genes with roles in cell division were negatively correlated with PtMD129 (Table 1). This supports the hypothesis that secondary wall integrity signaling results in coordination between cell division and secondary wall formation activities in developing wood (Ratke et al., 2018).

The network for PtMD110, which together with PtMD111 forms a pair orthologous to AtHERK2, included a homolog of the Arabidopsis gene encoding the transcription factor BES1-INTERACTING MYC-LIKE1 (AtBIM1) (Fig. 7B; Table 1; Table S8), which mediates brassinosteroid signaling (Chandler et al., 2009). Several other genes discussed above can be linked to BR-dependent or BES-related BRindependent signaling (Table 1). Intriguingly, a secondary wall xylan defect induced transcriptomic changes suggesting stimulation of BR signaling in aspen (Ratke et al., 2018), supporting the involvement of the AtBIM1 homolog in sensing secondary wall integrity. 


\section{Conclusions}

Malectin and malectin-like domains (MD/MLD) are lectin-like motifs found in proteins (MD proteins) of pro- and eukaryotes; they are particularly abundant in plants, where they carry out essential signaling functions in defense and development (Bellande et al., 2017; Franc et al., 2018). Recent studies have identified and classified MD genes in herbaceous plants (Zhang et al., 2016; Bellande et al., 2017; Sultana et al., 2019; Jing et al., 2020). Here we carried out a census of MD genes in the model woody species P. trichocarpa (Table S1) and expanded the set for $A$. thaliana (Table S2).

In total, $146 \mathrm{MD}$ genes were found in P. trichocarpa and they were assigned to fourteen clades based on sequence similarity, and to five superclades based on predicted protein domain organization and intron-exon structures (Figs. 1 and 2). The variety of $M D$ protein structures reflects their range of different functions in plants.

Certain $M D$ genes appeared to be specific either to trees or to the Populus lineage and absent from Arabidopsis. The prevalence of tandem duplications within the $M D$ gene family, which apparently led to family expansion, may have created conditions conducive to gene neofunctionalization and rapid evolution (Choi et al., 2016; Schaper and Anisimova, 2015).

The majority of the poplar $M D$ genes were found to be highly expressed in leaves, particularly those subjected to biotic and abiotic stress conditions (Fig. 5), supporting their role in stress signaling. Detailed analysis of expression in wood forming tissues revealed subsets upregulated in xylem cells during secondary wall deposition (Fig. 6). These genes, not unexpectedly, include candidates for the sensing of cell wall integrity. We identified their co-expression networks revealing potential molecular pathways in which these $M D$ genes might participate to ensure the coordination of secondary wall formation (Table 1). This study provides a framework for future investigations aiming at elucidating stress and developmental signaling pathways operating in trees.

\section{Materials And Methods}

\section{Identification of $P$. trichocarpa proteins with malectin and malectin-like domains}

The MD proteins of black cottonwood ( $P$. trichocarpa Torr. \& A. Gray) were identified by BLAST searches in the genome browser of the PopGenlE database (http://popgenie.org) containing $P$. trichocarpa genome assembly v3.0, using as baits the $P$. trichocarpa proteins containing Pfam domains 11721 and 12819, corresponding to MD and MLD respectively, retrieved from the Pfam database (https://pfam.xfam.org) (El-Gebali et al., 2019). The same approach was applied to $A$. thaliana using the TAIR database (v. 10.0) for BLAST searches (http://www.arabidopsis.org/). The presence of MDs/MLDs in the proteins selected for both $P$. trichocarpa and $A$. thaliana was confirmed using the CDvist web tool (http://cdvist.zhulinlab.org) (Adebali et al., 2015), which also served to identify other conserved domains in these proteins. The amino acid sequence lengths, molecular weights, isoelectric points and indices of protein stability of the putative proteins were calculated using the ProtParam tool provided on the ExPASy website (https://web.expasy.org/protparam/). The presence of signal peptides and subcellular localization were predicted with the SignalP 4.1 server (http:// www.cbs.dtu.dk/services/SignalP/) (Petersen et al. 2011) and DeepLoc-1.0 server (http://www.cbs.dtu.dk/services/DeepLoc/) (Armenteros et al. 2017) respectively. The exon-intron organization of the PtMD genes was determined using the PopGenIE GBrowse tool (http://popgenie.org/gbrowse) and their localization was mapped to P. trichocarpa chromosomes using the chromosome-diagram tool (http://popgenie.org/chromosome-diagram). Assignment of a gene to a gene cluster on each chromosome was based on the definition of Holub (2001).

\section{Phylogenetic analysis and classification of the MD proteins of $P$. trichocarpa}

All PtMD proteins identified were classified into clades based on phylogenetic analysis with $A$. thaliana. The amino acid sequences were aligned by MUSCLE (http://phylogeny.lirmm.fr/phylo_cgi/index.cgi) and phylogenetic trees were constructed using the neighbor-joining $(\mathrm{NJ})$ method in the MEGA7 software package with a bootstrap test with 1000 replicates (Kumar et al., 2016).

To identify the conserved residues in MD and MLD regions of poplar MD proteins, these regions were aligned with reference sequences using Jalview Version 2 (Waterhouse et al., 2009) with the MAFFT option (Katoh et al., 2005).

\section{Expression of PtMDs in different organs of Populus}

RNA-Seq datasets of expression values in different tissues/organs of outdoor and greenhouse grown aspen ( $P$. tremula L.) and hybrid aspen (P. tremula L. $x$ tremuloides Michx.) are available from the PlantGenIE website (Sundell et al., 2015), and those for secondary 
tissues of greenhouse grown hybrid aspen are detailed by Immanen et al. (2016). The data retrieved were normalized and used for hierarchical clustering and determination of tau tissue/organ specificity scores as explained by Kumar et al., (2019). The customized R scripts used in analyzing these datasets are available at https://github.com/UPSCb/UPSCb/tree/master/manuscripts/Kumar2018 and the corresponding data are available from the FTP repository: $\mathrm{ftp}$ ://ftp.plantgenie.org/Publications/Kumar2018. A heatmap was generated using ComplexHeatmap (Gu et al., 2016), an R (R Core Team, 2014) package designed for customizing heatmaps.

\section{PtMDs involved in wood biosynthesis}

The AspWood high-spatial-resolution RNA-Seq dataset (Sundell et al., 2017) was used for analysis of expression of PtMDs during wood biosynthesis. Identity of wood developmental zones was based on the expression of marker genes (Sundell et al., 2017). A heatmap of PtMD expression in wood developmental zones was constructed for one representative tree (tree 1) using the AspWood server (http://aspwood.popgenie.org/aspwood-v3.0/).

\section{Co-expression analysis}

Ten PtMD genes showing maximum expression in the CA-RE/PW-SW zone, and eight genes with maximum expression in either the PWSW/secondary wall zone or the secondary wall zone (Figure 6; Table S6) were used as 'Guide Genes' to obtain co-expression networks for developing secondary tissues, using the AspWood website (http://aspwood.popgenie.org/aspwood-v3.0/). The corresponding GraphML files were generated using the ExNet tool (http://popgenie.org/exnet) with a Z-score threshold of 5.0, and visualized using Cytoscape 3.4.0 (Shannon et al., 2003).

\section{Declarations}

\section{Ethics approval and consent to participate}

Not applicable.

\section{Consent for publication}

Not applicable.

\section{Availability of data and materials}

All data generated or analyzed during this study are included in this published article [and its supplementary information files].

\section{Competing interests}

The authors declare that they have no competing interests.

\section{Funding}

This work was supported by VR, the Kempe foundation, the Knut and Alice Wallenberg Foundation, and the SSF program ValueTree RBP14-0011.

\section{Authors' contributions}

VK identified MD-genes and their chromosomal clustering, and wrote the first draft; VK and FB identified protein domains and the main clades of MD-genes; VK and SK analyzed exon-intron structures; VK and END analyzed gene expression; END, JU and VK analyzed conserved regions in MD and MLD of poplar; VK and FB analyzed co-expression networks; EJM conceived and coordinated the project, and finalized the manuscript with contributions from all authors.

\section{References}

1. Adebali O, Ortega DR, Zhulin IB. CDvist: a webserver for identification and visualization of conserved domains in protein sequences. Bioinformatics. 2015;31:1475-7.

2. Armenteros JJA, Sønderby CK, Sønderby SK, Nielsen H, Winther O. DeepLoc: prediction of protein subcellular localization using deep learning. Bioinformatics. 2017;33:3387-95. 
3. Antignani V, Klocko AL, Bak G, Chandrasekaran SD, Dunivin T, Nielsen E. Recruitment of PLANT U-BOX13 and the PI4K $\beta 1 / \beta 2$ phosphatidylinositol-4 kinases by the small GTPase RabA4B plays important roles during salicylic acid-mediated plant defense signaling in Arabidopsis. Plant Cell. 2015;27:243-61.

4. Asai T, Tena G, Plotnikova J, Willmann MR, Chiu W-L, Gomez-Gomez L, Boller T, Ausubel FM, Sheen J. MAP kinase signalling cascade in Arabidopsis innate immunity. Nature 2002;415:977-83

5. Bella J, Hindle KL, McEwan PA, Lovell SC. The leucine-rich repeat structure. Cell Mol Life Sci. 2008;65:2307-33.

6. Bellande K, Bono JJ, Savelli B, Jamet E, Canut H. Plant lectins and lectin receptor-like kinases: How do they sense the outside? Int J Mol Sci. 2017;18:1164.

7. Bi G, Zhou Z, Wang W, Li L, Rao S, Wu Y, Zhang X, Menke FLH, Chen S, Zhou JM. Receptor-like cytoplasmic kinases directly link diverse pattern recognition receptors to the activation of mitogen-activated protein kinase cascades in Arabidopsis. Plant Cell. 2018;30:1543-61.

8. Boisson-Dernier A, Lituiev DS, Nestorova A, Franck CM, Thirugnanarajah S, Grossniklaus U. ANXUR receptor-like kinases coordinate cell wall integrity with growth at the pollen tube tip via NADPH oxidases. PLOS Biol. 2013;11:e1001719.

9. Boisson-Dernier A, Franck CM, Lituiev DS, Grossniklaus U. Receptor-like cytoplasmic kinase MARIS functions downstream of CrRLK1L-dependent signaling during tip growth. Proc Natl Acad Sci USA. 2015;112:12211-16

10. Campbell L, Turner SR. A comprehensive analysis of RALF proteins in green plants suggests there are two distinct functional groups. Front Plant Sci. 2017;8:37.

11. Chandler JW, Cole M, Flier A, Werr W. BIM1, a bHLH protein involved in brassinosteroid signalling, controls Arabidopsis embryonic patterning via interaction with DORNROSCHEN and DORNROSCHEN-LIKE. Plant Mol Biol. 2009;69:57-68.

12. Chen W, Lv M, Wang Y, Wang PA, Cui Y, Li M, Wang R, Gou X, Li J. BES1 is activated by EMS1-TPD1-SERK1/2-mediated signaling to control tapetum development in Arabidopsis thaliana. Nat Commun. 2019;10:4164.

13. Choi K, Reinhard C, Serra H, Ziolkowski PA, Underwood CJ, Zhao X, Hardcastle TJ, Yelina NE, Griffin C, Jackson M, Mézard C, McVean G, Copenhaver GP, Henderson IR. Recombination rate heterogeneity within Arabidopsis disease resistance genes. PloS Genet. 2016;12:e1006179.

14. Crawford BC, Sewell J, Golembeski G, Roshan C, Long JA, Yanofsky MF. Plant development. Genetic control of distal stem cell fate within root and embryonic meristems. Science. 2015;347:655-9.

15. Crooks GE, Hon G, Chandonia JM, Brenner SE. WebLogo: A sequence logo generator. Genome Res. 2004;14:1188-90.

16. Denness L, McKenna JF, Segonzac C, Wormit A, Madhou P, et al. Cell wall damage-induced lignin biosynthesis is regulated by a reactive oxygen species- and jasmonic acid-dependent process in Arabidopsis. Plant Physiol. 2011;156:1364-74

17. Draeger C, Ndinyanka Fabrice T, Gineau E, Mouille G, Kuhn BM, Moller I, Abdou MT, Frey B, Pauly M, Bacic A, Ringli C. Arabidopsis leucine-rich repeat extensin (LRX) proteins modify cell wall composition and influence plant growth. BMC Plant Biol. 2015;15:155.

18. Du C, Li X, Chen J, Chen W, Li B, et al. Receptor kinase complex transmits RALF peptide signal to inhibit root growth in Arabidopsis. Proc Natl Acad Sci USA. 2016;113:E8326-34

19. Du S, Qu LJ, Xiao J. Crystal structures of the extracellular domains of the CrRLK1L receptor-like kinases ANXUR1 and ANXUR2. Protein Sci. 2018;27:886-92.

20. Duan Q, Kita D, Li C, Cheung AY, Wu HM. FERONIA receptor-like kinase regulates RHO GTPase signaling of root hair development. Proc Natl Acad Sci USA. 2010;107:17821-6.

21. Dünser K, Gupta S, Herger A, Feraru MI, Ringli C, Kleine-Vehn J. Extracellular matrix sensing by FERONIA and Leucine-Rich Repeat Extensins controls vacuolar expansion during cellular elongation in Arabidopsis thaliana. EMBO J. 2019;38:e100353.

22. El-Gebali S, Mistry J, Bateman A, Eddy SR, Luciani A, Potter SC, Qureshi M, Richardson LJ, Salazar GA, Smart A, Sonnhammer ELL, Hirsh L, Paladin L, Piovesan D, Tosatto SCE, Finn RD. The Pfam protein families database in 2019. Nucleic Acids Res. 2019;47(D1):D427-D432.

23. Engelsdorf T, Hamann T. An update on receptor-like kinase involvement in the maintenance of plant cell wall integrity. Ann Bot. 2014;114:1339-47.

24. Escobar-Restrepo J-M, Huck N, Kessler S, Gagliardini V, Gheyselinck J, et al. The FERONIA receptor-like kinase mediates male-female interactions during pollen tube reception. Science 2007;317:656-60

25. Feng W, Kita D, Peaucelle A, Cartwright HN, Doan V, Duan Q, Liu M-C, Maman J, Steinhorst L, Schmitz-Thom I, Yvon R, Kudla J, Wu HM, Cheung AY, Dinneny JR. The FERONIA Receptor Kinase Maintains Cell-Wall Integrity during Salt Stress through $\mathrm{Ca}^{+2}$ Signaling.

Page 9/22 
Curr Biol. 2018;28: 666-75

26. Fisher K, Turner S. PXY, a receptor-like kinase essential for maintaining polarity during plant vascular-tissue development. Curr Biol. 2007; 17:1061-6.

27. Foreman J, Demidchik V, Bothwell JHF, Mylona P, Miedema H, et al. Reactive oxygen species produced by NADPH oxidase regulate plant cell growth. Nature 2003;422:442-6

28. Franck CM, Westermann J, Boisson-Dernier A. Plant malectin-like receptor kinases: from cell wall integrity to immunity and beyond. Ann Rev of Plant Biol 2018;69:301-28.

29. Galindo-Trigo S, Gray JE, Smith LM. Conserved roles of CRRLK1L receptor-like kinases in cell expansion and reproduction from algae to angiosperms. Front Plant Sci. 2016;7:1269.

30. Galindo-Trigo S, Grand TM, Voigt CA, Smith LM. A malectin domain kinesin functions in pollen and seed development in Arabidopsis. J Exp Bot 2020, advance access doi:10.1093/jxb/eraa023

31. Gatz C. From pioneers to team players: TGA transcription factors provide a molecular link between different stress pathways. Mol Plant Microbe Interact. 2013;26:151-9.

32. Ge Z, Bergonci T, Zhao Y, Zou Y, Du S, et al. Arabidopsis pollen tube integrity and sperm release are regulated by RALF-mediated signaling. Science. 2017;358:1596-600

33. Gish LA, Clark SE. The RLK/Pelle family of kinases. Plant J. 2011;66:117-27.

34. Gonneau M, Desprez T, Martin M, Doblas VG, Bacete L, Miart F, Sormani R, Hématy K, Renou J, Landrein B, Murphy E, Van De Cotte B, Vernhettes S, De Smet I, Höfte H. Receptor kinase THESEUS1 is a rapid alkalinization factor 34 receptor in Arabidopsis. Curr Biol. 2018;28:2452-8.

35. Gu Z, Eils R, Schlesner M. Complex heatmaps reveal patterns and correlations in multidimensional genomic data. Bioinformatics. 2016;32: 2847-9.

36. Haga K, Frank L, Kimura T, Schwechheimer C, Sakai T. Roles of AGCVIII kinases in the hypocotyl phototropism of Arabidopsis seedlings. Plant Cell Physiol. 2018;59:1060-71.

37. Hamann T. The plant cell wall integrity maintenance mechanism--a case study of a cell wall plasma membrane signaling network. Phytochemistry. 2015;112:100-9.

38. Haruta M, Sabat G, Stecker K, Minkoff BB, Sussman MR. A peptide hormone and its receptor protein kinase regulate plant cell expansion. Science. 2014;343:408-11.

39. Hématy K, Sado PE, Van Tuinen A, Rochange S, Desnos T, Balzergue S, Pelletier S, Renou JP, Hofte H. A receptor-like kinase mediates the response of Arabidopsis cells to the inhibition of cellulose synthesis. Curr Biol. 2007;17: 922-31.

40. Holub EB. The arms race is ancient history in Arabidopsis, the wildflower. Nat Rev Genet. 2001;2:516-27.

41. Hou C, Tian W, Kleist T, He K, Garcia V, Bai F, Hao Y, Luan S, Li L. DUF221 proteins are a family of osmosensitive calcium-permeable cation channels conserved across eukaryotes. Cell Res. 2014;24:632-5.

42. Huang C, Zhang R, Gui J, Zhong Y, Li L. The receptor-like kinase AtVRLK1 regulates secondary cell wall thickening. Plant Physiol. 2018;177:671-83.

43. Immanen J, Nieminen K, Smolander OP, Kojima M, Alonso Serra J, Koskinen P, Zhang J, Elo A, Mähönen AP, Street N, Bhalerao RP, Paulin L, Auvinen P, Sakakibara H, Helariutta Y. Cytokinin and auxin display distinct but interconnected distribution and signaling profiles to stimulate cambial activity. Curr Biol. 2016;26:1990-7.

44. Jing XQ, Shalmani A, Zhou MR, Shi P-T, Muhammad I, Shi Y, Sharif R, Li W-Q, Liu W-T, Chen K-M. Genome-wide identification of malectin/malectin-like domain containing protein family genes in rice and their expression regulation under various hormones, abiotic stresses, and heavy metal treatments. J Plant Growth Regul. 2020;39:492-506.

45. Katoh K, Kuma K, Toh H, Miyata T. MAFFT version 5: improvement in accuracy of multiple sequence alignment. Nucleic Acids Res. 2005;33:511-8.

46. Kessler SA, Shimosato-Asano H, Keinath NF, Wuest SE, Ingram G, Panstruga R, Grossniklaus U. Conserved molecular components for pollen tube reception and fungal invasion. Science 2010;330: 968-71.

47. Khan M, Ragni L, Tabb P, Salasini BC, Chatfield S, Datla R, Lock J, Kuai X, Després C, Proveniers M, Yongguo C, Xiang D, Morin H, Rullière JP, Citerne S, Hepworth SR, Pautot V. Repression of lateral organ boundary genes by pennywise and pound-foolish is essential for meristem maintenance and flowering in Arabidopsis. Plant Physiol. 2015;169:2166-86. 
48. Kong L, Cheng J, Zhu Y, Ding Y, Meng J, Chen Z, Xie Q, Guo Y, Li J, Yang S, Gong Z. Degradation of the ABA co-receptor ABI1 by PUB12/13 U-box E3 ligases. Nat Commun. 2015;6:8630.

49. Kumar S, Stecher G, Tamura K. MEGA7: Molecular evolutionary genetics analysis version 7.0 for bigger datasets. Mol Biol Evol. 2016;33:1870-4.

50. Kumar V, Hainaut M, Delhomme N, Mannapperuma C, Immerzeel P, Street NR, Henrissat B, Mellerowicz EJ. Poplar carbohydrateactive enzymes: whole-genome annotation and functional analyses based on RNA expression data. Plant J. 2019;99:589-609.

51. Le MH., Cao, Y., Zhang, X. C., Stacey, G. LIK1, A CERK1-interacting kinase, regulates plant immune responses in Arabidopsis. PlosONE 2014;9: e102245.

52. Li C, Wu HM, Cheung AY. FERONIA and Her Pals: Functions and Mechanisms. Plant Physiol. 2016;171:2379-92.

53. Li N, Muthreich M, Huang LJ, Thurow C, Sun T, Zhang Y, Gatz C. TGACG-BINDING FACTORs (TGAs) and TGA-interacting CC-type modulate hyponastic growth in Arabidopsis thaliana. New Phytol. 2019;221:1906-18.

54. Liao D, Cao Y, Sun X, Espinoza C, Nguyen CT, Liang Y, Stacey G. Arabidopsis E3 ubiquitin ligase PLANT U-BOX13 (PUB13) regulates chitin receptor LYSIN MOTIF RECEPTOR KINASE5 (LYK5) protein abundance. New Phytol. 2017;214:1646-56.

55. Liebsch D, Sunaryo W, Holmlund M, Norberg M, Zhang J, Hall HC, Helizon H, Jin X, Helariutta Y, Nilsson O, Polle A, Fischer U. Class I KNOX transcription factors promote differentiation of cambial derivatives into xylem fibers in the Arabidopsis hypocotyl. Development. 2014;141:4311-9.

56. Liu J, Li W, Ning Y, Shirsekar G, Cai Y, Wang X, Dai L, Wang Z, Liu W, Wang GL. The U-Box E3 ligase SPL11/PUB13 is a convergence point of defense and flowering signaling in plants. Plant Physiol. 2012;160:28-37.

57. Liu J, Rice JH, Chen N, Baum TJ, Hewezi T. Synchronization of developmental processes and defense signaling by growth regulating transcription factors. PLoS ONE 2014;9: e98477.

58. Liu X, Wang J, Sun L. Structure of the hyperosmolality-gated calcium-permeable channel 0SCA1.2. Nat Commun. 2018;9:5060.

59. Liu H, Xiong F, Duan C-Y, Wu Y-N, Zhang Y, Li Sha. Importin $\beta 4$ mediates nuclear import of GRF-interacting factors to control ovule development in Arabidopsis. Plant Physiol 2019;179:1080-92.

60. Mang H, Feng B, Hu Z, Boisson-Dernier A, Franck C, et al. 2017. Differential regulation of two-tiered plant immunity and sexual reproduction by ANXUR receptor-like kinases. Plant Cell 29:3140-56

61. Mayfield JD, Folta KM, Paul AL, Ferl RJ. The 14-3-3 Proteins mu and upsilon influence transition to flowering and early phytochrome response. Plant Physiol. 2007;145:1692-702.

62. Meng J-G, Liang L, Jia P-F, Wang Y-C, Li H-J, Yang W-C. Integration of ovular signals and exocytosis of a Ca ${ }^{2+}$ channel by MLOs in pollen tube guidance. Nature Plants 2020;6:143-53.

63. Merz D, Richter J, Gonneau M, Sanchez-Rodriguez C, Eder T, et al. T-DNA alleles of the receptor kinase THESEUS1 with opposing effects on cell wall integrity signaling. J. Exp. Bot. 2017;68:4583-93

64. Miao Y, Laun T, Zimmermann P, Zentgraf U. Targets of the WRKY53 transcription factor and its role during leaf senescence in Arabidopsis. Plant Mol Biol. 2004;55:853-67.

65. Mineev KS, Bocharov EV, Pustovalova YE, Bocharova OV, Chupin VV, Arseniev AS. Spatial structure of the transmembrane domain heterodimer of ErbB1 and ErbB2 receptor tyrosine kinases. J Mol Biol. 2010;400:231-43.

66. Mori K, Renhu N, Naito M, Nakamura A, Shiba H, Yamamoto T, Suzaki T, lida H, Miura K. Ca²+-permeable mechanosensitive channels MCA1 and MCA2 mediate cold-induced cytosolic $\mathrm{Ca}^{2+}$ increase and cold tolerance in Arabidopsis. Sci Rep. $2018 ; 8: 550$.

67. Moussu S, Augustin S, Roman A-O, Broyart C, Santiago J. Crystal structures of two tandem malectin-like receptor kinases involved in plant reproduction. Acta Cryst. 2018;D74, 671-80.

68. Omidbakhshfard MA, Fujikura U, Olas JJ, Xue GP, Balazadeh S, Mueller-Roeber B. GROWTH-REGULATING FACTOR 9 negatively regulates arabidopsis leaf growth by controlling ORG3 and restricting cell proliferation in leaf primordia. PLoS Genet. 2018;14:e1007484.

69. Pagnussat GC, Yu H-J, Ngo QA, Rajani S, Mayalagu S, Johnson CS, Capron A, Xie L-F, Ye D, Sundaresan V. Genetic and molecular identification of genes required for female gametophyte development and function in Arabidopsis. Development 2005;132: 603-14.

70. Petersen TN, Brunak S, von Heijne G, Nielsen H. SignalP 4.0: discriminating signal peptides from transmembrane regions. Nat Methods. 2011;8:785-6.

71. Pinard D, Mizrachi E, Hefer CA, Kersting AR, Joubert F, Douglas CJ, Mansfield SD, Myburg AA. Comparative analysis of plant carbohydrate active enZymes and their role in xylogenesis. BMC Genomics. 2015;16:402.

Page 11/22 
72. Prunet N, Morel P, Champelovier P, Thierry AM, Negrutiu I, Jack T, Trehin C. SQUINT promotes stem cell homeostasis and floral meristem termination in Arabidopsis through APETALA2 and CLAVATA signalling. J Exp Bot. 2015;66:6905-16.

73. R Core Team. R: A language and environment for statistical computing. R Foundation for Statistical Computing, Vienna, Austria. 2014;URL http://www.R-project.org/.

74. Rao S, Zhou Z, Miao P, Bi G, Hu M, Wu Y, Feng F, Zhang X, Zhou J-M. Roles of receptor-like cytoplasmic kinase VII members in pattern-triggered immune signaling. Plant Physiol. 2018;177:1679-90.

75. Ratke C, Terebieniec BK, Winestrand S, Derba-Maceluch M, Grahn T, Schiffthaler B, Ulvcrona T, Özparpucu M, Rüggeberg M, Lundqvist SO, Street NR, Jönsson LJ, Mellerowicz EJ. Downregulating aspen xylan biosynthetic GT43 genes in developing wood stimulates growth via reprograming of the transcriptome. New Phytol. 2018;219:230-45.

76. Rubinovich L, Weiss D. The Arabidopsis cysteine-rich protein GASA4 promotes GA responses and exhibits redox activity in bacteria and in planta. Plant J. 2010;64:1018-27.

77. Rui Y, Dinneny JR 2020. A wall with integrity: surveillance and maintenance of the plant cell wall under stress. New Phytol. 2020;225:1428-39

78. Schallus T, Jaeckh C, Fehér K, Palma AS, Liu Y, Simpson JC, Mackeen M, Stier G, Gibson TJ, Feizi T, Pieler T, Muhle-Goll C. Malectin: a novel carbohydrate-binding protein of the endoplasmic reticulum and a candidate player in the early steps of protein $\mathrm{N}$ glycosylation. Mol Biol Cell. 2008;19:3404-14.

79. Schallus T, Fehér K, Sternberg U, Rybin V, Muhle-Goll C. Analysis of the specific interactions between the lectin domain of malectin and diglucosides. Glycobiology. 2010;20:1010-20.

80. Schaper E, Anisimova M. The evolution and function of protein tandem repeats in plants. New Phytol. 2015;206:397-410.

81. Shannon P, Markiel A, Ozier O, Baliga NS, Wang JT, Ramage D, Amin N, Schwikowski B, Ideker T. Cytoscape: a software environment for integrated models of biomolecular interaction networks. Genome Res. 2003;13:2498-504.

82. Shiu SH, Bleecker AB. Receptor-like kinases from Arabidopsis form a monophyletic gene family related to animal receptor kinases. Proc Natl Acad Sci U S A. 2001;98:10763-8.

83. Shiu SH, Bleecker AB. Expansion of the receptor-like kinase/Pelle gene family and receptor-like proteins in Arabidopsis. Plant Physiol. 2003;132:530-43.

84. Smith MR, Willmann MR, Wu G, Berardini TZ, Möller B, Weijers D, Poethig RS. Cyclophilin 40 is required for microRNA activity in Arabidopsis. Proc Natl Acad Sci USA. 2009;106:5424-9.

85. Song H, Guo Z, Chen T, Sun J, Yang G. Genome-wide identification of LRR-containing sequences and the response of these sequences to nematode infection in Arachis duranensis. BMC Plant Biol. 2018;18:279.

86. Stegmann M, Monaghan J, Smakowska-Luzan E, Rovenich H, Lehner A, Holton N, Belkhadir Y, Zipfel C. The receptor kinase FER is a RALF-regulated scaffold controlling plant immune signaling. Science. 2017;355:287-9.

87. Sultana MM, Hachiya T, Dutta AK, Nishimura K, Suzuki T, Tanaka A, Nakagawa T. Expression analysis of genes encoding malectinlike domain (MLD)- and leucine-rich repeat (LRR)- containing proteins in Arabidopsis thaliana. Bioscience, Biotechnology, and Biochemistry. 2019;doi:10.1080/09168451.2019.1661769.

88. Sundell D, Mannapperuma C, Netotea S, Delhomme N, Lin YC, Sjödin A, Van de Peer Y, Jansson S, Hvidsten TR, Street NR. The plant genome integrative explorer resource: PlantGenIE.org. New Phytol. 2015;208:1149-56.

89. Sundell D, Street NR, Kumar M, Mellerowicz EJ, Kucukoglu M, Johnsson C, Kumar V, Mannapperuma C, Delhomme N, Nilsson O, Tuominen H, Pesquet E, Fischer U, Niittylä T, Sundberg B, Hvidsten TR. AspWood: high-spatial-resolution transcriptome profiles reveal uncharacterized modularity of wood formation in Populus tremula. Plant Cell. 2017;29:1585-604.

90. Swarup K, Benková E, Swarup R, Casimiro I, Péret B, Yang Y, Parry G, Nielsen E, De Smet I, Vanneste S, et al. The auxin influx carrier LAX3 promotes lateral root emergence. Nature Cell Biol 2008;10: 946-54.

91. Thole JM, Vermeer JE, Zhang Y, Gadella TW Jr, Nielsen E. Root hair defective4 encodes a phosphatidylinositol-4-phosphate phosphatase required for proper root hair development in Arabidopsis thaliana. Plant Cell. 2008;20:381-95.

92. Voxeur A, Höfte H. Cell wall integrity signaling in plants: "To grow or not to grow that's the question". Glycobiology. 2016;26:950-60.

93. Wang G, Ellendorff U, Kemp B, Mansfield JW, Forsyth A, Mitchell K, Bastas K, Liu CM, Woods-Tör A, Zipfel C, de Wit PJ, Jones JD, Tör M, Thomma BP. A genome-wide functional investigation into the roles of receptor-like proteins in Arabidopsis. Plant Physiol. 2008;147:503-17. 
94. Wang J, Kucukoglu M, Zhang L, Chen P, Decker D, Nilsson O, Jones B, Sandberg G, Zheng B. The Arabidopsis LRR-RLK, PXC1, is a regulator of secondary wall formation correlated with the TDIF-PXY/TDR-WOX4 signaling pathway. BMC Plant Biol. 2013;13:94.

95. Wang J, Hu T, Wang W, Hu H, Wei Q and Bao C. Investigation of evolutionary and expressional relationships in the function of the leucine-rich repeat receptor-like protein kinase gene family (LRR-RLK) in the radish. Sci Rep 2019a; 9:6937.

96. Wang Y, Salasini BC, Khan M, Devi B, Bush M, Subramaniam R, Hepworth SR. Clade I TGACG-motif binding basic leucine zipper transcription factors mediate BLADE-ON-PETIOLE-dependent regulation of development. Plant Physiol. 2019b;180:937-951.

97. Wolf S, Höfte H. Growth control: a saga of cell walls, ROS, and peptide receptors. Plant Cell. 2014;26:1848-56.

98. Wolf S. Plant cell wall signalling and receptor-like kinases. Biochem J. 2017;474:471-92.

99. Won S-K, Lee Y-J, Lee H-Y, Heo Y-K, Cho M, Cho H-T. Cis-element- and transcriptome-based screening of root hair-specific genes and their functional characterization in Arabidopsis. Plant Physiol. 2009;150:1459-73

100. Waterhouse AM, Procter JB, Martin DMA, Clamp M, Barton GJ. Jalview Version 2 - a multiple sequence alignment editor and analysis workbench. Bioinformatics. 2009;25:1189-91.

101. Xi J, Qiu Y, Du L, Poovaiah BW. Plant-specific trihelix transcription factor AtGT2L interacts with calcium/calmodulin and responds to cold and salt stresses. Plant Sci. 2012;185-186:274-80.

102. Xi L, Wu XN, Gilbert M, Schulze WX. Classification and interactions of LRR receptors and co-receptors within the Arabidopsis plasma membrane - An overview. Front Plant Sci. 2019;10:472.

103. Xiao Y, Stegmann M, Han Z, DeFalco TA, Parys K, Xu L, Belkhadir Y, Zipfel C, Chai J. Mechanisms of RALF peptide perception by a heterotypic receptor complex. Nature. 2019;572:270-4.

104. Yang Y, Labbé J, Muchero W, Yang X, Jawdy SS, Kennedy M, Johnson J, Sreedasyam A, Schmutz J, Tuskan GA, Chen JG. Genomewide analysis of lectin receptor-like kinases in Populus. BMC Genomics. 2016;17:699.

105. Yeh Y-H, Panzeri D, Kadota Y, Huang Y-C, Huang P-Y, Tao C-N, Roux M, Chien H-C, Chin T-C, Chu P-W, Zipfel C, Zimmerli L. The Arabidopsis Malectin-Like/LRR-RLK IOS1 is critical for BAK1-dependent and BAK1-independent pattern-triggered immunity. Plant Cell. 2016;28:1701-21.

106. Yuan N, Yuan S, Li Z, Zhou M, Wu P, Hu Q, Mendu V, Wang L, Luo H. STRESS INDUCED FACTOR 2, a leucine-rich repeat kinase regulates basal plant pathogen defense. Plant Physiol 2018;176: 3062-80.

107. Zan Y1, Ji Y, Zhang Y, Yang S, Song Y, Wang J. Genome-wide identification, characterization and expression analysis of Populus leucine-rich repeat receptor-like protein kinase genes. BMC Genomics. 2013;14:318.

108. Zhang Q, Jia MR, Xing Y, Qin L, Li BB, Jia WS. Genome-wide identification and expression analysis of MRLK family genes associated with strawberry (Fragaria vesca) fruit ripening and abiotic stress responses. PLoS 0NE 2016;11:e0163647.

109. Zhong R, Ye ZH. MYB46 and MYB83 bind to the SMRE sites and directly activate a suite of transcription factors and secondary wall biosynthetic genes. Plant Cell Physiol. 2012;53:368-80.

110. Zhou J, Liu D, Wang P, Ma X, Lin W, Chen S, Mishev K, Lu D, Kumar R, Vanhoutte I, Meng X, He P, Russinova E, Shan L. Regulation of Arabidopsis brassinosteroid receptor BRI1 endocytosis and degradation by plant U-box PUB12/PUB13-mediated ubiquitination. Proc Natl Acad Sci USA. 2018;115:E1906-15.

111. Zulawski M, Schulze G, Braginets R, Hartmann S, Schulze WX. The Arabidopsis Kinome: phylogeny and evolutionary insights into functional diversification. BMC Genomics. 2014;15:548.

\section{Tables}

Table 1. Genes co-regulated with poplar MD genes expressed during secondary wall formation that were discussed in the text. All genes from network analyses are listed in Tables S7 and S8. 


\begin{tabular}{|c|c|c|c|c|c|c|c|c|c|c|c|c|}
\hline \multirow[t]{2}{*}{ First neighbors } & \multirow{2}{*}{$\begin{array}{l}\text { Poplar } \\
\text { name }\end{array}$} & \multirow{2}{*}{$\begin{array}{l}\text { Best } \\
\text { BLAST AGI } \\
\text { codes }\end{array}$} & \multirow{2}{*}{$\begin{array}{l}\text { Ath- } \\
\text { names }\end{array}$} & \multicolumn{7}{|c|}{ Baits } & \multirow[t]{2}{*}{ Ath short description } & \multirow[t]{2}{*}{ Pathway/proces: } \\
\hline & & & & \begin{tabular}{|l|} 
MD126 \\
(Potri.006G110000)
\end{tabular} & $\begin{array}{l}\text { MD94 } \\
\text { (Potri.010G213200) }\end{array}$ & $\mid \begin{array}{l}\text { MD98 } \\
\text { (Potri.001G405500) }\end{array}$ & \begin{tabular}{|l|} 
MD88 \\
(Potri.002G242700)
\end{tabular} & $\begin{array}{l}\text { MD129 } \\
\text { (Potri.008G105500) }\end{array}$ & $\begin{array}{l}\text { MD137 } \\
\text { (Potri.010G090800) }\end{array}$ & $\begin{array}{l}\text { MD110 } \\
\text { (Potri.001G467000) }\end{array}$ & & \\
\hline Potri.014G052700 & & AT5G47070 & PBL19 & + & & & & & & & \begin{tabular}{|l|} 
PBS1-LIKE 19 - a \\
RLCK \\
phosphorylating \\
MAPKKK5 and \\
MEKK1 in response \\
to chitin \\
\end{tabular} & $\begin{array}{l}\text { PAMP, ROS, P, } \\
\text { JA, and BR } \\
\text { signaling, } \\
\text { BOP1/2 }\end{array}$ \\
\hline Potri.002G090700 & & AT5G65210 & TGA1 & + & & & & & & & $\begin{array}{l}\text { TGA-BINDING } 1 \text { - a } \\
\text { bZIP TF, a redox- } \\
\text { controlled regulator } \\
\text { of SAR and } \\
\text { development }\end{array}$ & $\begin{array}{l}\text { PAMP, ROS, P, } \\
\text { JA, and BR } \\
\text { signaling, } \\
\text { BOP1/2 }\end{array}$ \\
\hline Potri.005G170500 & & AT1G77920 & TGA7 & - & & & & & & & $\begin{array}{l}\text { TGA-BINDING } 7 \text { - a } \\
\text { bZIP TF, a redox- } \\
\text { controlled regulator } \\
\text { of SAR and } \\
\text { development }\end{array}$ & $\begin{array}{l}\text { PAMP, ROS, P, } \\
\text { JA, and BR } \\
\text { signaling, } \\
\text { BOP1/2 }\end{array}$ \\
\hline Potri.004G213300 & & AT2G27990 & BLH8 & + & & & & & & & \begin{tabular}{|l|} 
Bel1-like TF, \\
regulating BOP1 and \\
integrating stress \\
signaling via JA \\
\end{tabular} & \begin{tabular}{|l} 
PAMP, ROS, P, \\
JA, and BR \\
signaling, \\
BOP1/2 \\
\end{tabular} \\
\hline Potri.001G392200 & & AT2G42590 & GRF9 & + & & & & & & & \begin{tabular}{|l|} 
GROWTH- \\
REGULATING \\
FACTOR 9, 14-3-3 \\
gene. Binds Ca+2 and \\
regulates \\
development. \\
\end{tabular} & $\begin{array}{l}\mathrm{Ca}^{2+} \text { and } \mathrm{P} \\
\text { signaling and } \\
\text { regulation }\end{array}$ \\
\hline Potri.010G169800 & & AT4G27640 & IMB4 & + & & & & & & & \begin{tabular}{|l} 
IMPORTIN-b 4 \\
transporting GRF- \\
interacting factor 1 \\
(GIF1) to nucleus \\
\end{tabular} & $\begin{array}{l}\mathrm{Ca}^{2+} \text { and } \mathrm{P} \\
\text { signaling and } \\
\text { regulation }\end{array}$ \\
\hline Potri.009G029600 & & AT3G46510 & PUB13 & & + & & & & & & $\begin{array}{l}\text { PLANT U-BOX 13, an } \\
\text { E3 ubiquitin ligase } \\
\text { involved in } \\
\text { ubiquitination of } \\
\text { receptor FLS2. }\end{array}$ & PAMP signaling \\
\hline Potri.005G100500 & & AT3G51460 & RHD4 & & + & & & & & & \begin{tabular}{|l} 
ROOT HAIR \\
DEFECTIVE4, a \\
phosphatidylinositol- \\
4-P phosphatase \\
required by root \\
hairs
\end{tabular} & $\begin{array}{l}\text { P signaling and } \\
\text { regulation }\end{array}$ \\
\hline Potri.015G108700 & & AT5G61820 & & & + & & & & & & $\begin{array}{l}\text { Stress up-regulated } \\
\text { Nod } 19 \text { protein; }\end{array}$ & $\begin{array}{l}\mathrm{Ca}^{2+} \text { and } \mathrm{P} \\
\text { signaling and } \\
\text { regulation }\end{array}$ \\
\hline Potri.017G059500 & & AT4G13950 & RALFL31 & & + & & & & & & \begin{tabular}{|l} 
RAPID \\
ALKALINIZATION \\
FACTOR LIKE 31 - \\
peptide hormone \\
\end{tabular} & $\begin{array}{l}\text { CrRLK1L - } \\
\text { mediated } \\
\text { signaling }\end{array}$ \\
\hline Potri.005G174000 & & AT1G77690 & LAX3 & & & + & & & & & $\begin{array}{l}\text { Auxin influx carrier } \\
\text { LAX3 (Like Aux1) }\end{array}$ & Auxin signaling \\
\hline Potri.010G236200 & & AT3G44610 & AGC1-12 & & & + & & & & & \begin{tabular}{|l} 
Kinase involved in \\
phototropism and \\
gravitropism. \\
Phosphorylates PIN1 \\
\end{tabular} & Auxin signaling \\
\hline Potri.017G083000 & & AT5G15230 & GASA4 & & & + & & & & & $\begin{array}{l}\text { Encodes GA-regulated } \\
\text { protein GASA4. } \\
\text { Promotes GA } \\
\text { responses and } \\
\text { exhibits redox } \\
\text { activity. } \\
\end{array}$ & GA signaling \\
\hline Potri.006G117200 & & AT2G36570 & PXC1 & & & + & & & & & $\begin{array}{l}\text { Leucine-rich repeat } \\
\text { protein kinase family } \\
\text { protein }\end{array}$ & $\begin{array}{l}\text { Xylogenesis and } \\
\text { SW formation }\end{array}$ \\
\hline Potri.001G057800| & & AT1G67310 & & & & - & & & & & $\begin{array}{l}\text { Calmodulin-binding } \\
\text { TF }\end{array}$ & $\begin{array}{l}\mathrm{Ca}^{2+} \text {-related } \\
\text { signaling }\end{array}$ \\
\hline Potri.001G126100 & & AT5G61480 & PXY & & & & + & & & & $\begin{array}{l}\text { PHLOEM } \\
\text { INTERCALATED } \\
\text { WITH XYLEM -a LRR- }\end{array}$ & $\begin{array}{l}\text { Xylogenesis and } \\
\text { SW formation }\end{array}$ \\
\hline
\end{tabular}

Page 14/22 


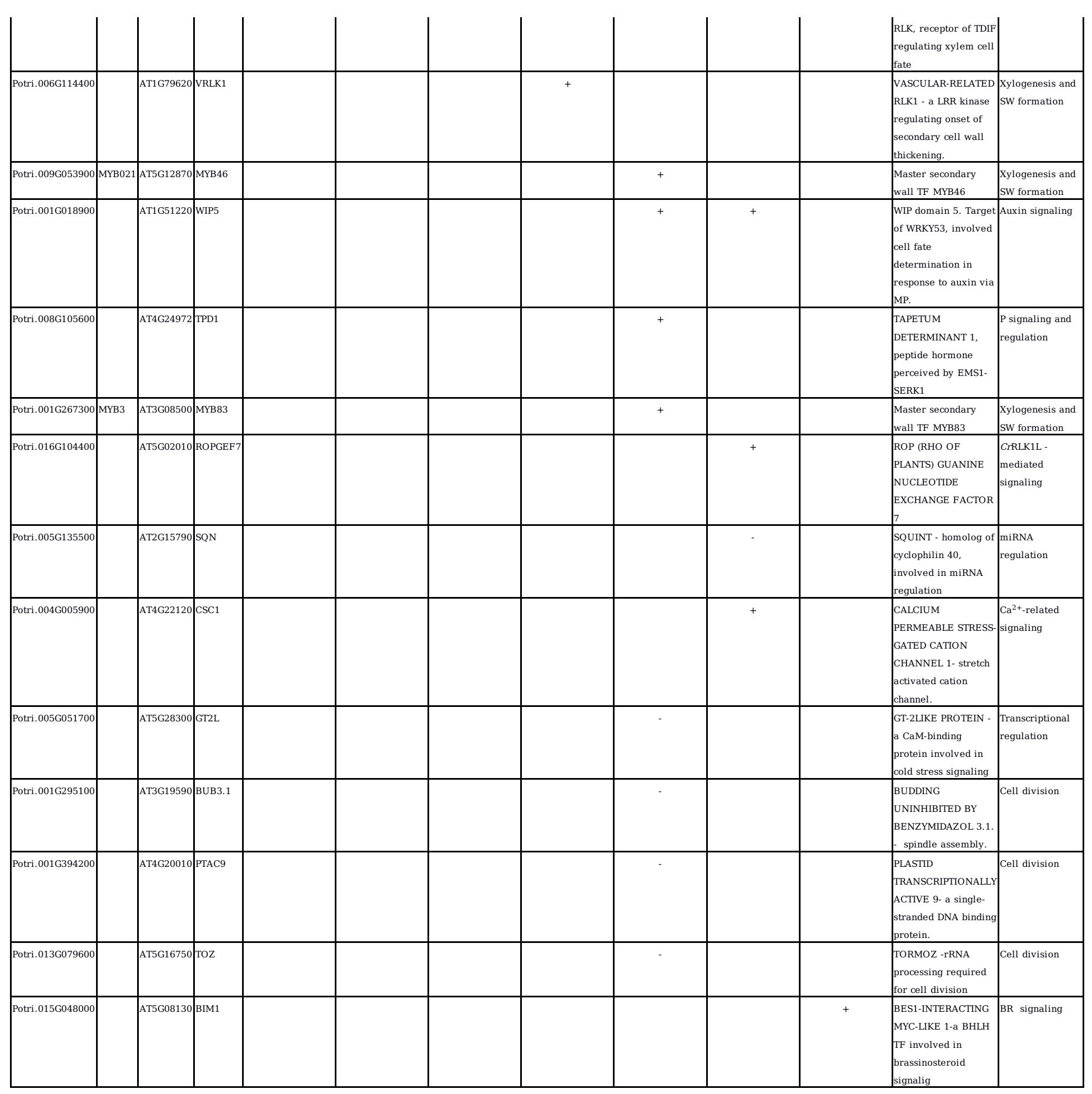

\section{Figures}




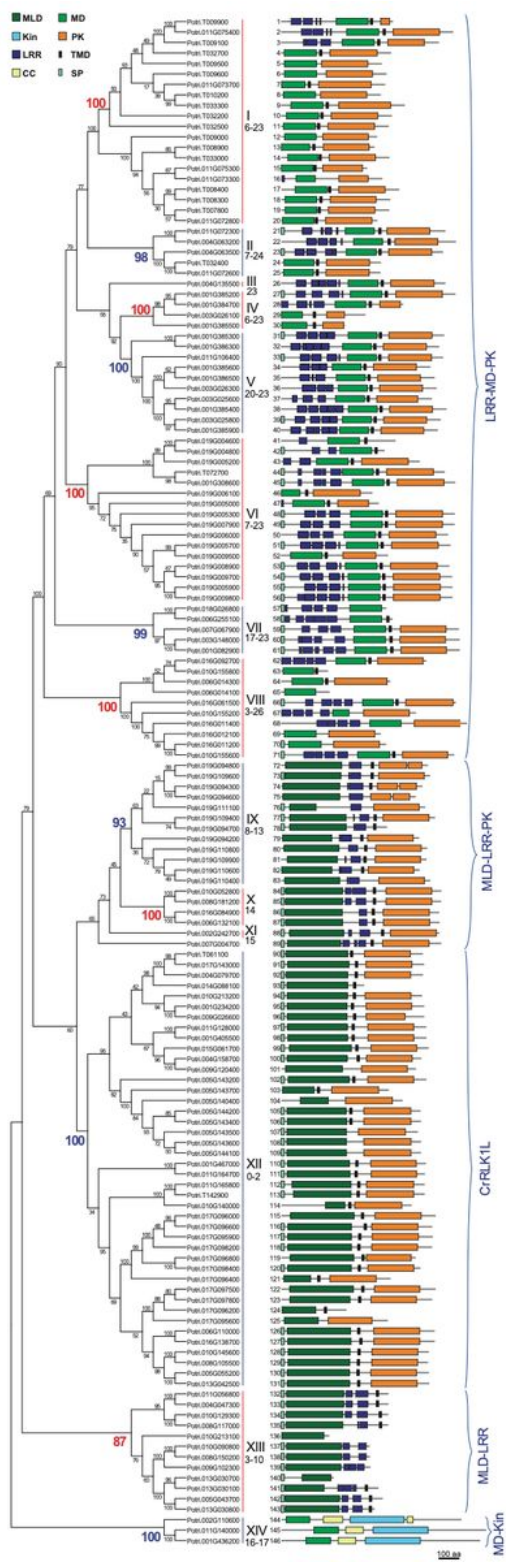

\section{Figure 1}

Phylogenetic tree of poplar malectin/malectin-like domain-containing proteins (PtMDs) showing their domain structures. The tree was constructed from MUSCLE-aligned amino acid sequences using the neighbor-joining method in MEGA 7.0 with 1000 bootstrap replicates and bootstrap support is displayed beside the nodes as percentages. PtMDs are identified by the number shown next to each protein structure. Domain abbreviations are: CC - coiled coil, Kin - kinesin, LRR - leucine-rich repeat, MD - malectin domain, MLD - malectinlike domain, PK - protein kinase, SP - signal peptide and TMD - transmembrane domain. Main clades are numbered with Roman numerals and their corresponding bootstrap values are colored in the phylogenetic tree. Numbers below the Roman numerals correspond to the number of introns observed within a clade. Five groups containing clades with similar protein domain structures are identified by the blue brackets: LRR-MD-PK (also known as poplar LRR-RLK XIII; Zan et al., 2013), MLD-LRR-PK (known as poplar LRR-RLK I; Zan et al., 2013), CrRLK1L, MLD-LRR, and MD-Kin. 


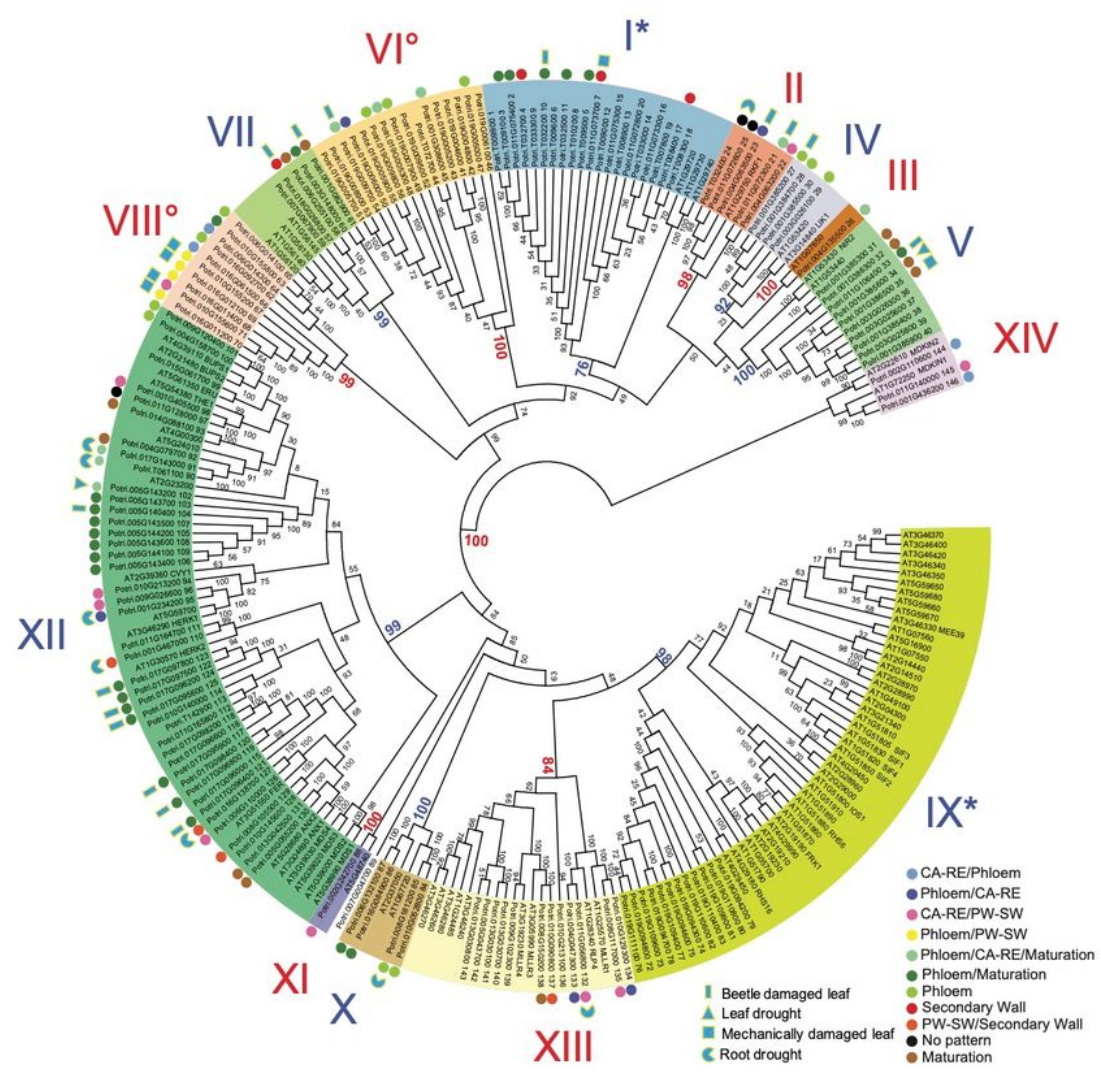

\section{Figure 2}

Phylogenetic tree of malectin/malectin-like domain-containing proteins in P. trichocarpa and A. thaliana. Each protein ID is followed by the name (A. thaliana) or PtMD protein number (P. trichocarpa). The phylogenetic tree was constructed based on MUSCLE-aligned amino acid sequences using the neighbor-joining method in MEGA 7.0 using 1000 bootstrap replicates, and the bootstrap support is displayed in percentages. Main clades are numbered with Roman numerals, and their supporting bootstrap values are shown in color. Colored dots beside PtMDs identify genes expressed in secondary vascular tissues based on the AspWood (http://aspwood.popgenie.org/aspwood-v 3.0/) database and showing maximum expression in different developmental zones as indicated by colors. CA-RE - cambium-radial expansion zone, PW-SW - primary to secondary wall transition zone. Blue shapes with yellow outlines show stress-related expression based on the aspen expression atlas available at http://popgenie.org. Degree symbols and asterisks beside Roman numerals indicate

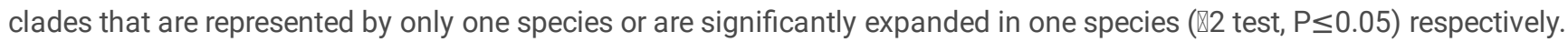




\section{Malectin domain (PF11721)}

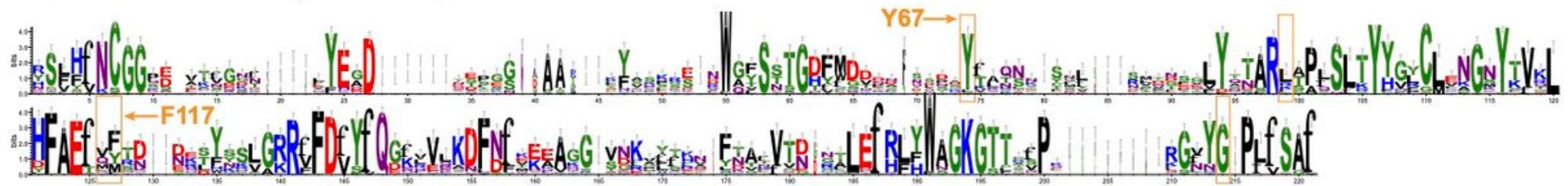

\section{Malectin-like domain (PF12819)}



\section{Figure 3}

Conserved motifs in malectin (top) and malectin-like (bottom) domains of P. trichocarpa. The residues involved in interaction with ligands according to Schallus et al. (2008) and Moussu et al. (2018) are shown in orange boxes. The amino acids conserved in P. trichocarpa are marked by arrows. The mutated residues in the THE1 protein in the the1 mutants studied (Hématy et al., 2007) are indicated by black asterisks. The logos were created based on P. trichocarpa MD/MLD amino acid sequence alignments by using the WebLogo 3.7.4 online tool (http://weblogo.threeplusone.com, Crooks et al. 2004). The conservation of amino acid residues is represented in bits and residues are colored according to chemical properties. The associated multiple sequence alignments are shown in Supplementary Figures S1 and S2. 


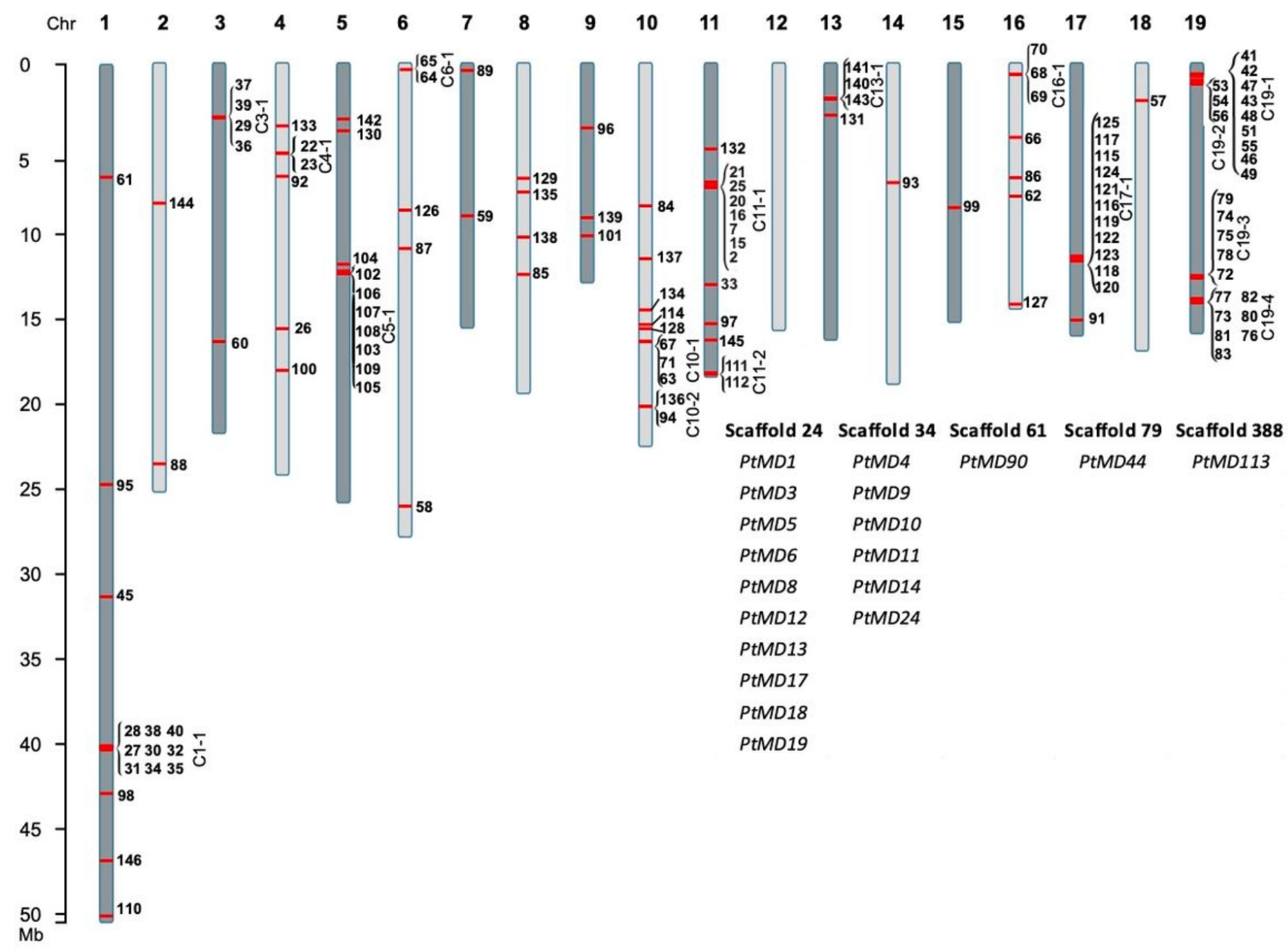

Figure 4

Chromosomal localization of the PtMD genes. The PtMD ID numbers are indicated beside chromosomes. Several PtMDs are found in clusters, shown by parentheses and labeled with a letter "C" followed by the chromosome number and the cluster number. Some PtMDs are on scaffolds, shown below the chromosomes. 




Figure 5

Heatmap of PtMD gene expression patterns in different organs of aspen. Data were retrieved from the aspen expression atlas available at http://popgenie.org and are listed in Table S5. 


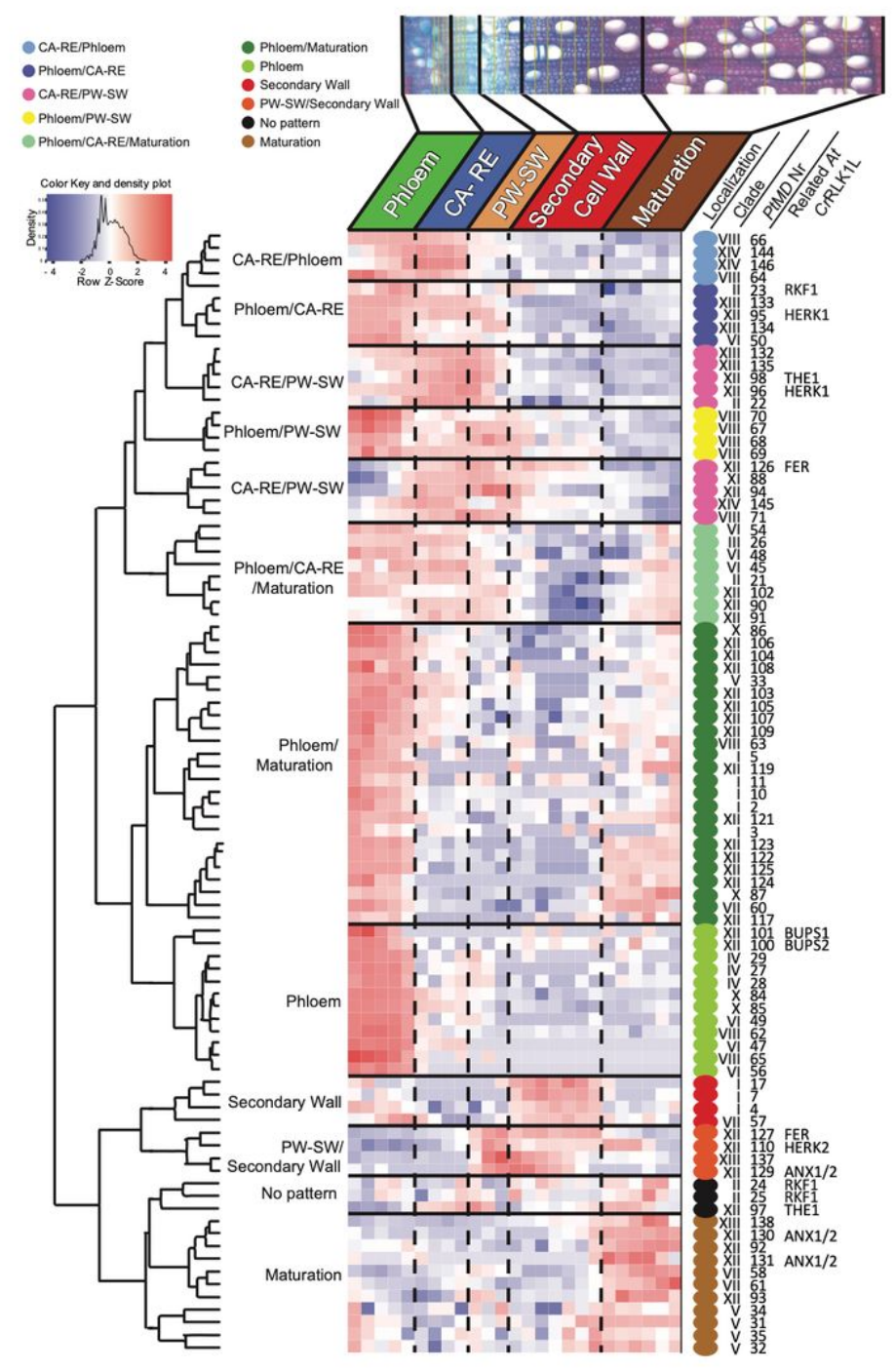

\section{Figure 6}

Heatmap of scaled PtMD expression patterns in developing secondary vascular tissues based on the AspWood database (http://aspwood.popgenie.org/aspwood-v3.0/). The majority of PtMD genes show maximum expression in the phloem and in the cambium-radial expansion zone (CA-RE). Smaller clusters of genes are expressed in the secondary wall formation zone, the transition between the primary and secondary wall zone (PW-SW), or the maturation zone. Specific wood developmental stages are defined based on the patterns of expression of marker genes (Sundell et al., 2017). Colored dots beside PtMDs identify groups with maximum expression in different developmental zones. 
A

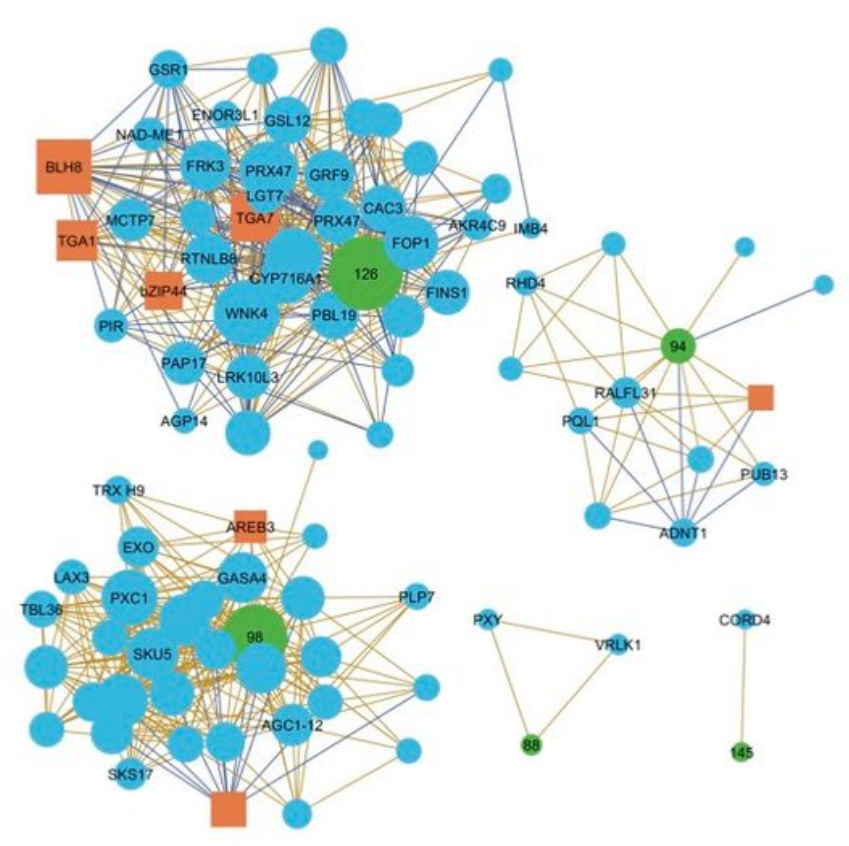

B



Figure 7

Co-expression networks of PtMDs in developing wood of aspen. The networks of genes expressed during the early (A) and main (B) stages of secondary wall deposition. The co-expressed genes were selected with threshold $=5$ from the AspWood database (http://aspwood.popgenie.org/aspwood-v3.0/) and visualized in Cytoscape v 3.4.0. The transcription factors are marked by orange rectangles and the PtMD genes, used as baits, by green circles with PtMD ID numbers. PtMD22, 71, 96, 132 and 135 did not have any coexpressed genes (not shown). The corresponding Arabidopsis gene names are used in the figures. Positive and negative correlations are shown by beige and blue lines respectively. The size of each marker corresponds to the number of correlations associated with it.

\section{Supplementary Files}

This is a list of supplementary files associated with this preprint. Click to download.

- TableS120200506.xlsx

- SupplementaryFigS2AB.pptx

- SupplementaryFigS1.pptx

- TableS320200506.xlsx

- Tables220200506.xlsx

- TableS420200506.xlsx

- TablesS5S820200506.xlsx 